\title{
Where elephants roam: perceived risk, vulnerability, and adaptation in the Okavango Delta
}

\author{
Lauren Redmore $^{1,2,3}$, Amanda L. Stronza ${ }^{1,3,4,5}$ Anna Songhurst $^{1,3,6}$ and Graham McCulloch $^{1,3,6}$
}

\begin{abstract}
Where people and elephants share space, the chance of human-elephant interactions (HEI) shape how people make livelihood decisions, including where and when to harvest resources. In the Eastern Panhandle of the Okavango Delta in Botswana, elephant populations have doubled in the past 10 years. Currently 16,000 men and women from different ethnic backgrounds share woodlands with 18,000 elephants. People carry out livelihoods in ways that are shaped by multiple facets of their identities, including gender, age, ability, and ethnicity. Residents depend on firewood for energy, but collecting firewood where elephants may be is risky because elephants can kill people. Using an intersectional approach, we asked how do facets of people's identities influence perceived risk, ability to adapt, and vulnerability to HEI? We conducted one year of mixed method, ethnographic research in the village of Mokgacha in the Eastern Panhandle. We found that both men and women collected elephant-felled firewood but had different perceptions of risk to HEI and adapted in different ways. Women often harvested in groups and the middle of the day, whereas men harvested alone in the morning and evenings while tending to cattle, leaving them vulnerable to elephants. Because of physical limitations, the elderly and people with disabilities were vulnerable to HEI and relied on resource sharing from family to reduce their vulnerability to HEI. Settlement history also influenced how people of different ethnicities are vulnerable because of access to environments with low visibility and higher chance of HEI. This work provides insights on who, how, and when people adapt to minimize the potential danger of HEI when collecting firewood. To reduce unwanted HEI and ensure continued support for elephants by rural residents, conservation interests should focus efforts on building solutions that recognize social diversity, recognize local perceptions of risk, and reinforce culturally relevant adaptations.
\end{abstract}

Key Words: human-elephant interactions; adaptation; identity; intersectionality; livelihoods; perceived risk; vulnerability

\section{INTRODUCTION}

For people who live with dangerous wildlife, the chances of unwanted interactions intimately shape how people behave and negotiate their environment. Human-wildlife interactions influence the ways that people and wildlife adapt to the other, and mutual adaptation is the key to the long-term survival of wildlife and improved societal well-being for people (Naughton et al. 1999, Carter and Linnell 2016, Redpath et al. 2017).

One crucial area of focus within human-wildlife interactions is that of humans and elephants. Negative human-elephant interactions (HEI) are problematic for both people and elephants: elephants consume crops and increase food insecurity in often food insecure rural areas; attack and kill livestock; and chase, injure, and even kill people. At the same time, people modify elephant habitat, and chase, injure, and sometimes kill elephants (Nelson et al. 2003, Lee and Graham 2006, Oswin Perera 2009, Mariki et al. 2015). For example, from 2009 to 2015, elephants were responsible for 1518 field raiding incidents, over half of all reported human-wildlife interactions, in the Eastern Panhandle of the Okavango Delta (Panhandle), Botswana (Pozo et al. 2020). In response, the Department of Wildlife and National Parks (DWNP) and farmers may kill elephants, and it is estimated that about 25 elephants are killed each year in the Panhandle (TippingWoods 2018). Devastatingly, human lives are also lost and in 2018 alone, elephants were responsible for the deaths of 36 people across Botswana (Chaukura et al. 2020). Even a single human death by an elephant may amplify the sense of risk (Kasperson et al. 1988) for residents, with the effect of reducing rural residents' tolerance for sharing space with wildlife (Carter et al. 2012).

Elephants, much like people, are long-lived and socially complex mammals (Sukumar 2003) known to avoid people in denselysettled areas (Pozo et al. 2017) and more likely to approach rural villages at night when people are at home (Buchholtz et al. 2019). People, similarly, modify their behaviors, including livelihood activities and settlement decisions to avoid elephants. For example, people may resettle in more population-dense villages to avoid elephants (Witter 2013), and they may reduce the time spent collecting natural resources (Ogra 2008, Mayberry et al. 2017).

HEI have recently been on the rise in Botswana where the elephant population has tripled in the past 20 years to between 130,000 and 142,000 elephants (Chase et al. 2016, Pozo et al. 2017). In the Panhandle, many people had never seen a live elephant prior to 20 years ago; now elephants are so ubiquitous that life is shaped by the ever-present possibility of unwanted HEI. Despite their size, elephants can be difficult to see as they easily blend into the wooded landscape. Elephants are quickly becoming the most dangerous animal for people who live in the Panhandle, and in the months following the conclusion of this research, two older men were killed by elephants while walking between Panhandle settlements (Charles 2018).

For people living in the Panhandle, firewood is often the only source of energy and people harvest only dead wood (Mmopelwa

\footnotetext{
${ }^{1}$ Applied Biodiversity Science Program, Texas A\&M University, ${ }^{2}$ Recreation, Park and Tourism Sciences Department, Texas A\&M University, ${ }^{3}$ The Ecoexist Project, Maun, Botswana, ${ }^{4}$ Department of Ecology and Conservation Biology, Texas A\&M University, ${ }^{5}$ Department of Rangeland, Wildlife, and Fisheries Management, Texas A\&M University, ${ }^{6}$ Department of Zoology, University of Oxford
} 
et al. 2009), which is legally allowed to be harvested for burning (Government of Botswana 1968). Men most often collect firewood alone, sometimes using donkey carts to carry up to several hundred kilograms of wood, while women most often collect in groups with children and carry smaller bundles on their heads (Arntzen and Kgathi 1984, Mmopelwa et al. 2009). People prefer to collect where firewood is abundant and as close as possible to their homes (Kgathi and Mlotshwa 1997). As settlements grow and proximate trees are cleared for space and to be used as building materials, people must harvest further into the woodlands (Agarwal 1986), which can be dangerous where elephants roam. However, given that elephants fell trees as they move through wooded landscapes, creating dried wood that people can harvest readily (Buchholtz et al. 2019), these dynamics are multifaceted and poorly understood.

Not only may people experience invisible costs, like psychological trauma from unwanted interactions when they harvest firewood where there are elephants (e.g., Ogra 2008, Mayberry et al. 2017), they can also perceive risk where omnipresent signs of elephants, including footprints, dung, and entire trees pushed over at the base, serve as daily reminders of their shared landscape. However, people are not passive victims and can adapt to changing realities to reduce chances of interactions. The goal of this research was to explore how people safely access firewood in the presence of elephants. Specifically, we asked: During firewood harvest, how do facets of people's identities, specifically gender, ethnicity, and age, influence (a) perceived risk to HEI, (b) ability to adapt to elephants, and (c) vulnerability to HEI?

This research was partly shaped around the death of a 65-yearold man from the Panhandle who ventured out into the woodlands behind his house to harvest firewood one cold winter evening in June 2016. He never came home, and when his adult daughter found his body the next day, the DWNP was summoned to kill the elephant that was suspected responsible for his death. Much remains to be understood about how people perceive, navigate, and adapt to the risk of HEI during firewood harvest.

\section{Perceived risk, adaptation, and vulnerability to elephants}

Risk perceptions are the judgments that people make about the likelihood of harm, negotiated internally through ideas of risk and externally through exposure to information (Dickman 2010, Lute and Gore 2019). Risk perceptions are both emotional and experiential and influence the decisions people make in their everyday lives (Dickman 2010, Lute and Gore 2019). As a result, perceived risk is shaped by facets of an individual's identity, such as gender, age, ability, ethnicity, and their personal values system (Starr 1969), and they can also be influenced by social networks (Wojcik 2011). Perceived risk is influenced by broader culture (Boholm 2003), institutional trust, communications, and real and perceived benefits (Slovic et al. 2000). Perceived risk impacts how people understand and respond to risk in ways that can change both the environment and society (Müller-Mahn 2012).

Perceived risk influences people's sense of antagonism toward wildlife and government authorities alike (Hill 2004, NaughtonTreves and Treves 2005). Scholars explain this phenomenon, in part, by whether individuals voluntarily choose to engage with the risk factor (Starr 1969). This means that for people who share space with dangerous wildlife, their perceived risk is often greater than the actual risk (Naughton-Treves and Treves 2005). People also view rare, devastating events to be more risky than frequent, small impact events (Naughton-Treves 2001) and perceive more threat from diurnal species, such as elephants, than from nocturnal species (Hill 2004)

People who are able to perceive and adapt to ecological or social change are thought to be less vulnerable to external threats (Turner et al. 2003, Smit and Wandel 2006, Miller et al. 2010, Maru et al. 2014). People have been adapting to their environment for millennia, though adaptation is not always possible when change is uncertain and comes rapidly (Pelling 2011). The ways in which people adapt depend on their individual traits and physical capacities, material culture, like technology, and social relations, practices, and values, among others (Pelling 2011).

Historically, researchers simplified who was considered vulnerable, often focusing on class and gender in binary terms that perpetuated victimization of those already lacking power (Djoudi et al. 2016). However, not all experiences of those with shared social attributes are the same. For instance, in the same way that men and women have different experiences with firewood harvest and HEI, many women have unique experiences with and approaches to firewood harvest and HEI. Driven by critiques from feminist political ecologists who show that individuals of the same group are not homogenous (Crenshaw 1991), the concept of intersectionality offers useful insights to understand how people may perceive risk and experience vulnerability differently (Carr and Thompson 2014, Ravera et al. 2016). Research that uses an intersectional lens to look at interactions across facets of identities has offered important insights into how women experience vulnerability differently (e.g., Mollett and Faria 2013, Doubleday 2020), and intersectionality has increasingly been used as a lens in conservation research for its ability to shed light on the diversity of experiences people of who live with wildlife (Rust and Taylor 2016, Homewood et al. 2020).

Increasingly, scholars recognize the need to understand how individuals' identities produce diverse vulnerability outcomes in the face of environmental threats (MacGregor 2009, Ryder 2017, Vickery 2018). Because vulnerability comprises the interactions across livelihoods, well-being, self-protection, social protection, and governance (Cannon 2008), fixed and mutable facets of people's identities, including gender, age, ability, ethnicity, and class, are also central to how people adapt to threats based on how they carry out livelihoods (Demetriades and Esplen 2008, Carr and Thompson 2014, Shinn et al. 2014). Intersectional identities shape livelihood practices with the potential for great consequence where people share space with elephants.

\section{STUDY SITE AND METHODS}

\section{Okavango Delta, Botswana}

This research was conducted in Botswana, a landlocked Southern African country. The study site is located on the banks of the Okavango Delta (Delta), a world-renowned UNESCO World Heritage Site and Ramsar Wetland of International Importance situated in the Kalahari Desert. The Delta is an inland alluvial floodplain that receives on average $490 \mathrm{~mm}$ of rainfall each year (McCarthy et al. 2000) and floods from May through September (McCarthy et al. 2003). The Delta hosts a diversity of animal and plant species that depend on its year-round water supply, and it is a major tourism attraction for the country, largely because of the ease of viewing elephants (Mbaiwa 2003). 
The Panhandle is a dry savanna woodland ecosystem the size of Yellowstone National Park $\left(\sim 8000 \mathrm{~km}^{2}\right)$. In the Panhandle, 18,000 elephants live with 16,000 people across 14 different villages and numerous smaller settlements, referred to as cattleposts (Central Statistics Office 2011, Pozo et al. 2017). The Panhandle is where three of the coauthors manage a nongovernmental organization (NGO), the Ecoexist Project (http://www.ecoexistproject.org), which works to reduce the impacts of unwanted HEI in the area.

Villages range in size from 500 to 5000 people, and most villages offer important social services, including schools, health clinics, and police stations. Some people also live in smaller, unofficial settlements called cattleposts, and access resources at the nearest village. All villages are headed by a village chief and an elected Village Development Committee, which is responsible for facilitating communication between residents and various government and NGO offices.

\section{Mokgacha Village}

The study village was Mokgacha and its associated cattleposts: Danga, Tinxo, Chinatown, Mawana, Nxiniha, and Kavumo (Fig. 1). Mokgacha was officially designated a village in 2013 and in 2018 had a total population of 530 ( 304 adults and 226 children), with an average age of 28 years old. Mokgacha was home to four different ethnic tribes, specifically Bayei, Bahambukushu, Boga Khwe, and //ani Khwe (Table 1). Households in Mokgacha had an average of 4 people and half the households were headed by women, mainly single mothers and widows.

Fig. 1. Map of study site showing the villages of the Eastern Panhandle of the Okavango Delta (inset A), as well as the study village, Mokgacha, with cattleposts (inset B).

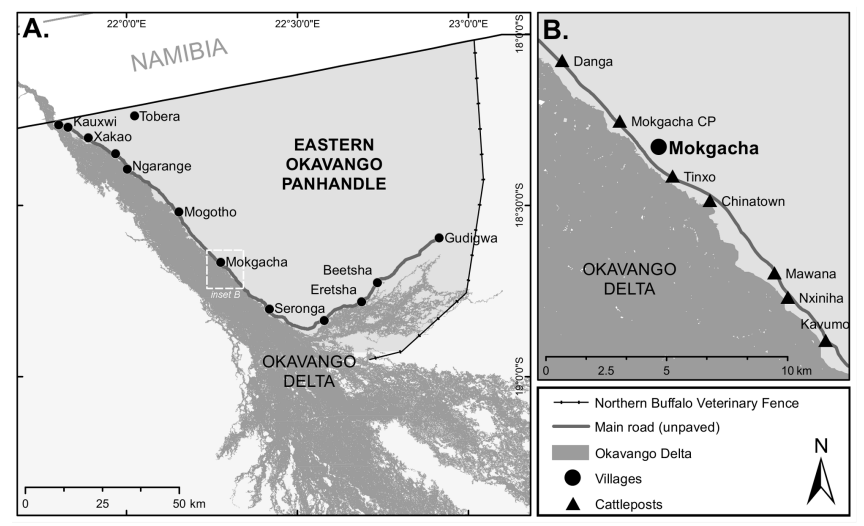

Mokgacha was chosen as the central study village because, unlike other villages in the area, it was not electrified and residents depended exclusively on firewood for all energy needs. Residents spent the large part of their day conducting a variety of livelihood activities, including washing clothes or fetching water at the Delta, harvesting and preparing food, tending to livestock, watching over children, and collecting firewood. People accessed different types of woodland ecosystems for firewood since environmental factors vary across the village and cattleposts.
Table 1. The different tribes inhabiting the study site according to the section of Mokgacha village where they settled.

\begin{tabular}{lc}
\hline \hline Tribe name & $\begin{array}{c}\text { Inhabiting section of Mokgacha } \\
\text { village }\end{array}$ \\
\hline //ani Khwe & North \\
BaHambukushu & North \\
Bayei & Central \\
Boga Khwe & South \\
\hline
\end{tabular}

\section{Methods}

Ethnographic research was conducted over the course of one year from May 2016 through July 2018 with the help of an assistant from Mokgacha village who spoke Setswana, English, and all four local languages. We lived in the village and relied on participant observation to inform study design and improve trustworthiness of the findings by gaining an emic, nuanced understanding of HEI and firewood harvest practices (Bernard 2006). Each night we recorded events from the day and created memos of key findings as they emerged throughout the research process, allowing us to take an inductive approach to data collection and analysis (Emerson 2001). Because we used an ethnographic approach, we allowed people's experiences and stories to guide theory development.

We used a sequential, mixed methods approach to guide methods development, narrowing in over time on theoretical and empirical findings (O'Reilly 2005). By taking a sequential approach, we built each method into the study as findings emerged around which identities mattered. By beginning with participant observation, we identified certain socio-cultural categories of importance, which we explored geographically by using a village-wide household census. We selected households and individuals according to the diversity of identities to conduct repeated firewood harvest focal follows, a firewood harvest survey, and interviews, as described below. By building and integrating both quantitative and qualitative data, we improved the validity of research results (Sale et al. 2002). We also improved credibility of findings by reporting back findings to community members in one-on-one interviews and community meetings (Moon et al. 2016).

\section{Household census}

We began collecting household data in each of the cattleposts and the village with the aim of introducing ourselves and to establish a population baseline, including livelihoods, ages, gender, and tribal identity of residents. We identified households initially by fenced-in yards, and by asking who eats from the same pot, following guidelines used by Botswana's national census (CSO 2001). Households were approached at least two additional times if an adult from the household was unavailable the first time.

We counted 122 households across all cattleposts $(n=14)$ and the village $(n=108)$. We were unable to capture 36 households in the census: 25 of those households spent most of the year in a different locality because of work or other circumstances; six were singlemember households and the household member was away from their homes each time; two households refused to participate 
because of research fatigue. With help from our assistant, we were able to enumerate the households we were unable to meet faceto-face, such that we had a complete count of households.

\section{Firewood harvest focal follows}

We conducted 54 firewood harvest focal follows (Alvard 1993) whereby we participated in firewood harvests with 14 ethnically diverse and geographically distinct households between two and five times according to the availability of members of the household (Table 2). For most of the firewood focal follows (n $=44$ ), participants were women because they do most of the firewood harvesting. We did, however, follow men when possible to better understand the diverse experience of firewood harvest.

Table 2. Firewood harvest focal follow $(n=54)$ schedule by household location indicating whether the harvest was conducted on foot $(\wedge)$, with a donkey cart $(*)$, or in a dugout canoe $(+)$.

\begin{tabular}{lccccc}
\hline \hline Household & Date & Date & Date & Date & Date \\
location & & & & & \\
\hline Mokgacha North & $12 / 17 / 17^{\wedge}$ & $2 / 4 / 18^{\wedge}$ & $2 / 23 / 18^{\wedge}$ & $6 / 6 / 18^{\wedge}$ & - \\
Mokgacha North & $12 / 5 / 17^{\wedge}$ & $2 / 7 / 18^{\wedge}$ & $4 / 5 / 18^{\wedge}$ & $5 / 29 / 18^{\wedge}$ & - \\
Mokgacha North & $2 / 9 / 18^{*}$ & $5 / 31 / 18^{*}$ & $6 / 15 / 18^{*}$ & $6 / 15 / 18^{\wedge}$ & - \\
Mokgacha North & $2 / 9 / 18^{\wedge}$ & $5 / 27 / 18^{\wedge}$ & $6 / 8 / 18^{\wedge}$ & $6 / 12 / 18^{\wedge}$ & - \\
Mokgacha North & $12 / 25 / 17^{*}$ & $5 / 30 / 18^{\wedge}$ & $6 / 1 / 18^{*}$ & $6 / 13 / 18^{\wedge}$ & - \\
Mokgacha & $12 / 22 / 17+$ & $3 / 1 / 18^{\wedge}$ & $5 / 31 / 18^{\wedge}$ & $6 / 11 / 18^{\wedge}$ & - \\
Central & & & & & \\
Mokgacha South & $12 / 8 / 18^{\wedge}$ & $4 / 2 / 18^{\wedge}$ & - & - & - \\
Mokgacha South & $2 / 5 / 18^{\wedge}$ & $3 / 7 / 18^{\wedge}$ & $5 / 26 / 18^{\wedge}$ & $6 / 9 / 18^{\wedge}$ & - \\
Danga & $2 / 13 / 18^{\wedge}$ & $2 / 23 / 18^{\wedge}$ & $3 / 5 / 18^{\wedge}$ & $3 / 22 / 18^{\wedge}$ & $5 / 30 / 18^{\wedge}$ \\
Danga & $2 / 13 / 18^{\wedge}$ & $6 / 10 / 18^{\wedge}$ & - & - & - \\
Tinxo & $2 / 15 / 18^{\wedge}$ & $2 / 28 / 18^{\wedge}$ & $3 / 7 / 18^{\wedge}$ & $3 / 21 / 18^{\wedge}$ & - \\
Kavumo & $2 / 16 / 18^{\wedge}$ & $3 / 2 / 18^{\wedge}$ & $4 / 6 / 18^{\wedge}$ & $5 / 30 / 18^{\wedge}$ & $6 / 12 / 18^{\wedge}$ \\
Mawana & $2 / 16 / 18^{\wedge}$ & $3 / 2 / 18^{\wedge}$ & $4 / 7 / 18^{\wedge}$ & $5 / 25 / 18^{\wedge}$ & - \\
Nxiniha & $3 / 2 / 18^{\wedge}$ & $3 / 28 / 18^{\wedge}$ & $4 / 6 / 18^{\wedge}$ & $6 / 8 / 18^{\wedge}$ & - \\
\hline
\end{tabular}

While in the woodlands, we examined each piece of wood harvested, identifying it by species and grouped it into one of three origin categories: "likely elephant-felled wood," "likely human-felled wood," and "other/unknown." We then used a hand-held luggage scale to weigh the amount of wood in each wood-felling origin category and documented the location of harvest and mode of transport. We also recorded each firewood harvest experience, noting signs of elephants, social interactions, and conversation.

\section{Firewood harvest survey}

We conducted a survey on firewood harvest practices with Mokgacha residents on firewood harvest and sharing. We were interested in understanding differences between gender and ages $(18-64,65+)$ on firewood harvest practices. Although many people 65 years and older collected firewood, including those with hearing and vision impairments, we identified the age of 65 as the cutoff because it is the age that national pension can be accessed, and it was also the lowest identified age in the range of adults over 18 years old who do not collect firewood as identified in our census. Survey questions focused on key risk behaviors, including time of harvest, whether they go with someone else, and who is most likely to share firewood with each other: nearby relatives, nearby nonrelatives, relatives living on the other side of the village, or nonrelatives living on the other side of the village.
We used the census data to identify a disproportionate stratified random sample (Bernard 2006) to ensure we sampled enough residents from all groups, in particular adults over the age of 65 because of their smaller population size (Table 3). We first stratified all residents according to age and gender and then randomized the order in which their names appeared. For men and women between the ages of 18 and 64 we surveyed over $25 \%$. For residents 65 years-old and over, we surveyed over $50 \%$. Individuals who were known to be currently residing out of town were removed from the list and replaced with other randomly selected names.

Table 3. Breakdown of stratified random sample of men and women by age according to total percentage of the population of Mokgacha village adult residents

\begin{tabular}{llc}
\hline \hline $\begin{array}{l}\text { Age } \\
\text { group }\end{array}$ & \multicolumn{2}{c}{ Men } \\
\hline $18-64$ & $\mathrm{n}=21(27 \%$ of 78 individuals $)$ & $\mathrm{n}=32(27 \%$ of 117 individuals $)$ \\
$65+$ & $\mathrm{n}=10(52 \%$ of 19 individuals $)$ & $\mathrm{n}=19(61 \%$ of 31 individuals $)$ \\
\hline
\end{tabular}

\section{Interviews}

We conducted open-ended interviews with 14 government and nongovernment representatives to ask about risk and vulnerability of residents to elephants in the study area. Government representatives were from Department of Forestry, DWNP, the local health clinic, among others. Other representatives included the village land overseer, the village chief, and the Okavango Community Trust village representative. In addition, we conducted semistructured interviews with 30 people from Mokgacha village. We used a purposive sampling strategy to identify residents, selecting for diversity in age, ethnicity, and geographic residence. We focused interview questions on resource sharing, residence location, and vulnerability to elephants. We stopped interviewing when we reached theoretical saturation and no new themes were heard (Guest et al. 2006). Our research was limited by the fact that we did not speak either Setswana or any of the local languages, which reduced the flow of conversations and restricted our understanding of potentially important dynamics.

\section{Data analysis}

We analyzed all participant observation and interview data over the course of the research process using an inductive and iterative approach to coding (O'Reilly 2005). Throughout the data collection process, we created memos, reflecting on findings and the data collection process, to assist in the data interpretation process (Bernard 2006). Using an ethnography-as-art combined with an ethnography-as-science approach (O'Reilly 2005, Wolcott 2005), we coded notes, transcripts, and documents for the key themes that emerged throughout the inductive research process, coding for both facets of socio-cultural identity and risk perception, vulnerability, and adaptation to HEI. We used quantitative data to show community and household composition, reveal patterns of village settlement, and describe firewood harvest practices (Bernard 2006). We grouped responses by key identities and ran Pearson's chi-square tests to determine differences between expected and observed frequencies to show differences between groups. 
Table 4. Summary findings showing how facets of identity played a role in livelihood dynamics, as well as how identities shaped vulnerability and adaptation to human-elephant interactions (HEI).

\begin{tabular}{|c|c|c|c|}
\hline & Gender & Age and ableness & Ethnicity \\
\hline Key livelihood dynamics & $\begin{array}{l}\text { Women were more frequently } \\
\text { responsible for key household chores, } \\
\text { including firewood harvest }\end{array}$ & $\begin{array}{l}\text { Elders had difficulty walking long } \\
\text { distances and carrying heavy loads, } \\
\text { instead collecting lower quality } \\
\text { firewood closer to home }\end{array}$ & $\begin{array}{l}\text { People who settled in the southern } \\
\text { section of the village had restricted } \\
\text { access to open woodlands because of } \\
\text { agricultural land uses, and often } \\
\text { harvested in the closed canopy forests } \\
\text { at the Delta's edge }\end{array}$ \\
\hline
\end{tabular}

dawn and dusk in low populationdensity areas

Key findings for how facets of identity shape adaptation to HEI

All residents harvested elephant-

felled firewood because of abundance

Women were more likely to collect firewood in groups for visibility Women were more likely to harvest firewood in the middle of the day

Key findings for how facets of identity shape vulnerability to HEI Men who cared for cattle were more vulnerable because of visitation to HEI-prone areas at dawn and dusk

Men were more vulnerable to HEI because they were less likely to travel with others because of scattered geography of cattle pens ( $\mathrm{kraal})$ and ideals of masculinity
People with impaired vision and hearing often still contributed to firewood harvest for household Family members from neighboring households shared firewood with elderly or family members with disabilities to reduce their exposure

Elders harvest low-quality firewood from around the village and may be less vulnerable

Visually or hearing-impaired individuals more vulnerable when harvesting in woodlands because they were not be able to readily identify elephant signs

\section{RESULTS AND DISCUSSION}

People were vulnerable and adapted to HEI in ways that were influenced by gender, age and ability, and ethnicity (Table 4). First, key capacities of the individual, such as impairments or strengths, were directly related to aspects of identity and have consequences for what someone can and cannot do. This is the reason we have categorized age and ability together throughout this research. We clarify that ability was not restricted to the elderly and was on many occasions a temporary limitation, for instance when someone was ill. Furthermore, ability was not always a physical restriction but in some cases a cultural restriction, such as when a young woman miscarried and taboos required her to remain isolated in a shelter for weeks at a time. Although age is not a fixed identity, for the purpose of this research we largely focused on the elderly and others with vision and hearing loss because of how common it was in the village.

Second, informal and formal institutions as wide-ranging as culture and policy, influenced how people engaged with and experienced their environment and surroundings. Livelihood demands and basic survival needs also determined where and how people accessed resources. These socioeconomic considerations interacted repeatedly to influence perceived risk, adaptation, and vulnerability, and we present our findings below according to facets of identity.

\section{Men and women alike harvested elephant-felled firewood}

The ways that elephants modify trees and woodlands provided new opportunities and challenges for all Mokgacha residents. On the most practical level, the harvest of elephant-felled firewood meant an overall reduction in the effort needed by residents to collect firewood. In $50 \%$ of firewood harvest focal follows $(\mathrm{n}=$ 27), people collected exclusively elephant-felled firewood. In only $15 \%$ of firewood harvest focal follows $(n=8)$, less than $50 \%$ of the harvested firewood was felled by elephants with the rest being sourced from human activity, usually waste wood from harvest of poles, or natural causes like insects or rot (Fig. 2). Between $90 \%$ and $100 \%$ of harvested firewood was generated by elephants in 33 out of 54 focal follows, and in 45 out of 54 focal follows more than $50 \%$ of firewood harvested was generated by elephants.

Fig. 2. The percentage of firewood harvested from elephantfelled wood during firewood harvest focal follows.

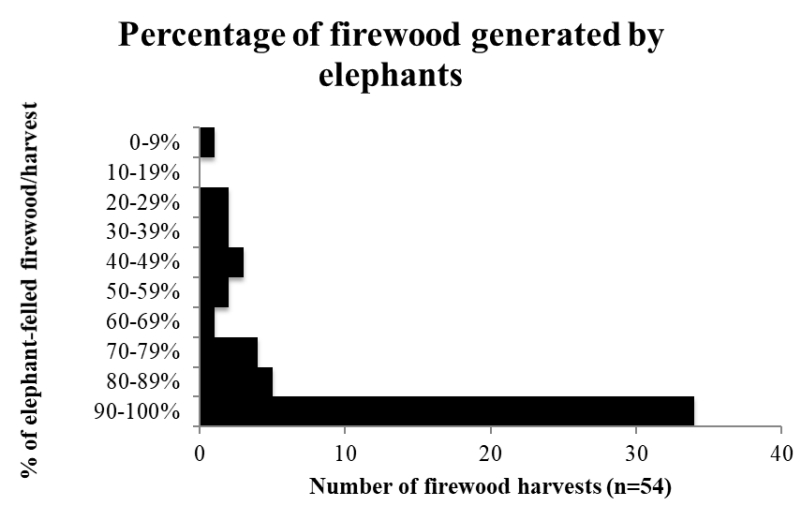


It was so common for people to harvest elephant-felled firewood that they would often report that they harvest intentionally in elephant pathways. For instance, one 65-year-old farmer was collecting firewood with her neighbors when she spotted what she quickly realized was an elephant's tusk camouflaged in the nearby brush. She quietly went to alert her neighbors and they quickly ran home, returning later to collect what they had hastily abandoned. She explained that she liked collecting in this "elephant pathway" because "we're used to collecting there and there's plenty of firewood." She, like many others, was not referring to the most heavily trafficked elephant corridors but to places where elephants generally frequent, marked by elephant footprints, dung, uprooting of shrubs, and tree and shrub browserelated damage. The intention to harvest elephant-felled firewood in elephant-trafficked areas illustrated how perceived risk can also be complemented by adaptation to new opportunity, highlighting people's ability to make the most of a bad situation.

\section{Women often modified firewood harvest practices because of perceived risk to $\mathrm{HEI}$}

Perceived risk influenced the time of day people regularly carried out firewood harvest. Most survey respondents (95\%) preferred to harvest after $8 \mathrm{AM}$ and before $5 \mathrm{PM}$ when elephants were less active around the village, with a significant difference between gender and preferred harvest times $\left(X^{2}(10, N=76)=26.07, p=\right.$ 0.003; Fig. 3). Women were more likely than men to factor elephant movement into their decision making $\left(X^{2}(1, N=77)=\right.$ $6.89, p=0.0086$; Fig. 4), suggesting that women changed firewood harvest time because of perceived risk to elephants. For example, one 16-year-old girl who harvested with her mom explained that "I harvest at 9 AM before it gets too hot [in the day], but not earlier because of elephants." In contrast, four men reported that they prefer to harvest at the tail ends of the day, likely because of prioritization of cattle-tending responsibilities in the early morning and late afternoons. None of those men incorporated perceived risk into their decisions for their firewood harvest times.

Fig. 3. There was a significant difference between men $(\mathrm{M})$ and women (F) for preferred firewood harvest times, $X^{2}(10, N=76)$ $=26.07, p=0.0036$.

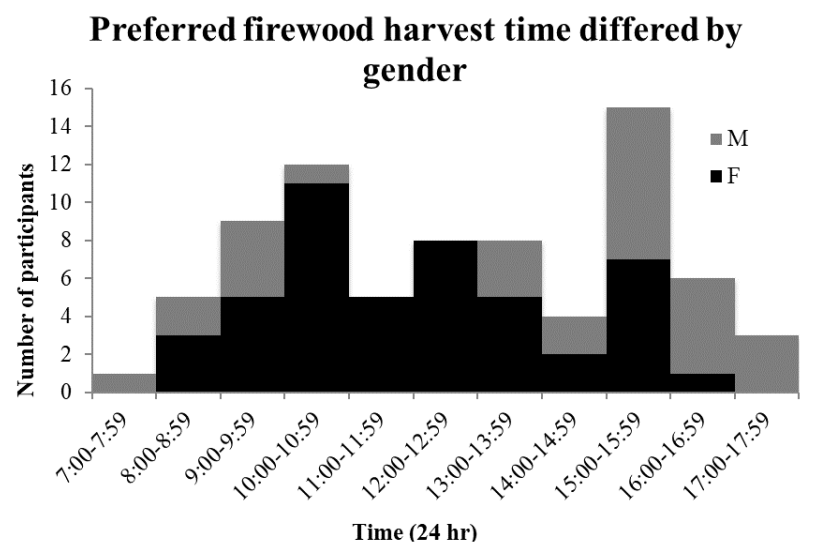

People also reduced their perceived risk and vulnerability to HEI by collecting firewood with others. Of those who perceived risks from harvesting alone (41 out of 77 survey respondents), expressed risks were elephants (61\%), wild animals (17\%), and danger, more generally $(17 \%)$. Harvesting of resources in groups was a cultural practice commonly used by women for selfprotection not just from HEI but also from other perceived dangers associated with being alone in the outdoors. In the same way that gender influenced whether people considered elephants when deciding what time to harvest firewood, women were more likely than men to consider risks to their security when deciding whether to harvest with others $\left(X^{2}(2, N=77)=8.51, p=0.014\right.$; Fig. 5).

Fig. 4. Women (F) were more likely than men (M) to account for elephant movement in deciding harvest firewood times, $X^{2}$ $(1, N=77)=6.89, p=0.0086$.

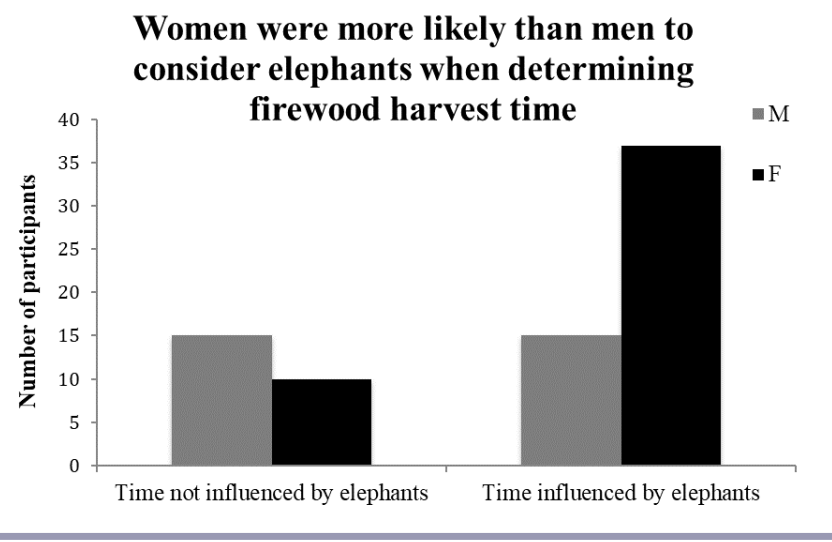

Fig. 5. Women were more likely to consider risk when deciding whether to harvest alone or with others, $X^{2}(2, N=77)=8.51, p$ $=0.014$.

\section{Gender influenced whether someone harvested in groups due to perceived risk}

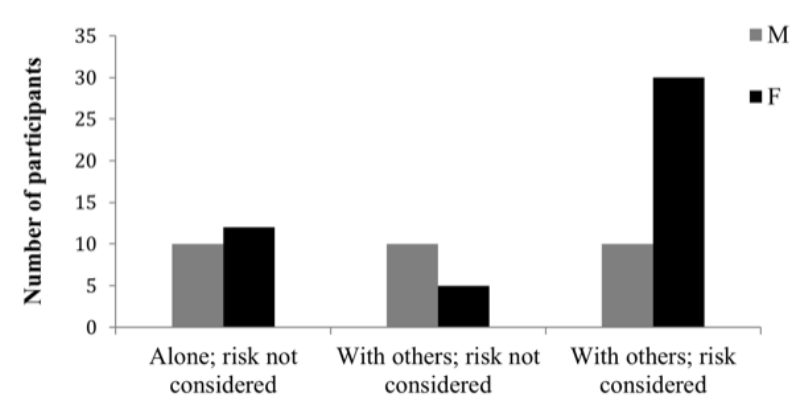

In some cases, residents cited numerous perceived risks that influence their firewood harvest behavior. A 44-year-old woman explained that she collected with others "to accompany each other because there are murderers [in the woodlands]." Although she modified the time she harvested firewood because of elephants, fear of violent encounters, perhaps with men, was a salient issue for her. Eight of 47 women cited fear of murderers as one reason they harvest in groups. It is likely that this also is linked to the 
sometimes-unknowable circumstances around people's tragic encounters with dangerous wildlife that sometimes leave even the DWNP and police wondering what happened to someone.

\section{Men were less likely to adapt because of cattle-based livelihoods and conceptions of masculinity}

In the same way that gender, culture, and livelihoods intersected to reduce women's vulnerability to HEI, they intersected with negative consequences for men. First, people often combined firewood harvest with other livelihood activities, for example, women harvested thatching grass and reeds during the dry season from August through November. They walked out into the floodplains each day, leaving their grasses and reeds to dry until the end of the season, returning home each day with firewood from the Delta islands. In a similar way, men who cared for cattle left their homes before sunrise each morning to make their way to their cattle kraal where they pen cattle each evening. Kraals are often geographically scattered, meaning men often traveled in the dark, either alone, with neighbors who have nearby kraals, or with their male children to teach them how to care for livestock. Usually they walked, but sometimes they rode horses or donkeys. Like women, men often combined firewood harvest at these tail ends of the day after tending to livestock.

Many men expressed that they felt safer from HEI when traveling with others; however, because of the nature of cattle-based livelihoods that required temporal precision in care, this was not always possible. For example, a 65 -year-old man and a 24 -yearold man, alike, both mentioned that they collected firewood on their way back home from the kraal. Both men traveled in the company of family and friends with neighboring kraals, allowing them greater chances of spotting elephants early and reducing their vulnerability to HEI. In contrast, one 21-year-old man explained that he collected by himself on his way home from the kraal because, "People are busy with their own work at home."

Instead of relying on other people to help keep an eye out for elephants, some men carried long-barreled guns into the woodlands or Delta. A DWNP officer noted that the types of guns were generally not the correct caliber for killing elephants, and "it puts them [men] actually at greater risk because of aggravated injury to animals which means only that they [wildlife] get angry and can kill people." Furthermore, perceptions of masculinity influenced behavior, as one DWNP officer further explained,

Going out alone poses the biggest threat, and we get reports of missing people, but no one can say where they were or what they were doing. Actually, men are at greater risk [to dangerous wildlife] because they think they're brave and they go alone, while women go in groups.

This mentality of bravery was exemplified by a 54-year-old man who, when asked why he preferred to harvest firewood early in the morning, declared, "I'm a man and I'm not afraid of elephants." Combined with cattle-based livelihoods, ideals of how men were "supposed" to act brave likely exacerbated genderspecific vulnerabilities to HEI.

\section{Family reduced vulnerability for the elderly and people with} disabilities

Despite people's efforts to adapt to life with elephants, age and ability remained critical factors influencing vulnerability to HEI.
A DWNP officer explained, "Most young people aren't having problems with elephants as compared to old people who can't see or hear well." Vision impairments amongst the elderly were fairly common. Six out of 29 survey respondents $(20 \%)$ over the age of 65 were significantly visually impaired, often with cataracts, and depended on their family to assist them in daily tasks or to share resources with them. Many elders and people with vision problems relied on company during firewood harvest to reduce risks. For instance, a 57-year-old man who collected firewood with his wife explained that they go together "because my wife has good vision and can see if elephants are coming." Similarly, a 69year-old woman explained that she collects with others because "I can't see properly and can encounter an elephant if I'm alone."

However, not everyone had equal access to the company of others. In total, $71 \%(n=55)$ of participants harvested with others, while elderly residents $(71+$ years of age) were more likely than other adults $(18-70$ years of age $)$ to harvest alone $\left(X^{2}(1, N=77)=\right.$ $10.69, p=0.011$; Fig. 6). As a 76-year-old woman explained, "I have no one to go with and am not strong enough to go long distances." For some elderly residents, age and ability combined in this way to alienate them from the security of harvesting firewood with others.

Fig. 6. Men and women $71+$ years of age harvested alone more often than men and women 18-70 years of age, $X^{2}(1, N=77)=$ $10.69, p=0.011$.

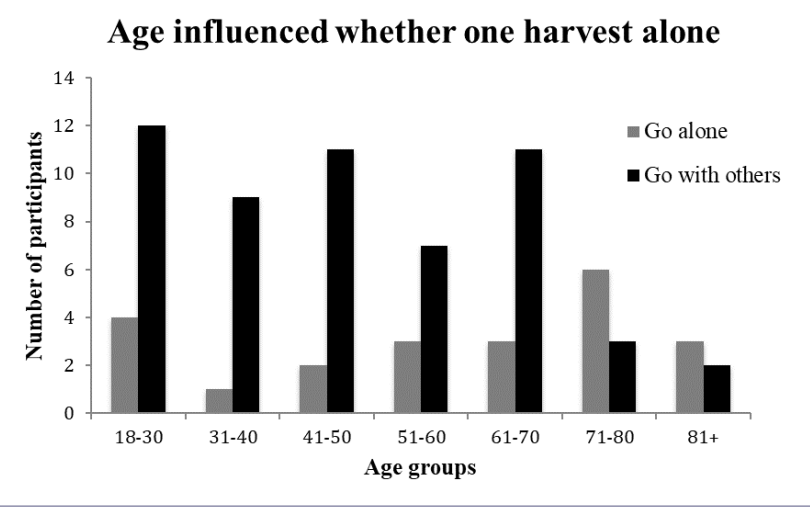

For residents who had no one to harvest with, the sharing of firewood was an important aspect of culture that also reduced vulnerability to HEI. Resource sharing, especially amongst nearby relatives, was common and expected. When asked who was the last person to give them firewood, $65 \%(n=53$ of 81$)$ of survey respondents received firewood from a relative, while $25 \%$ $(n=21)$ of respondents could not recall anyone giving them firewood.

Family support was critical, especially for those with physical disabilities because they would be especially vulnerable to HEI while engaging in everyday livelihoods. One 30-year-old woman who lived with her own young children next to her elderly mother explained, "When I have a headload of firewood, I separate it in half and give my mom one half. She is old and she cannot go out to collect firewood alone." By provisioning firewood to older relatives, younger residents reduced the need for elders to go out to harvest on their own. In exchange, elders often stayed home 
and cared for young children. This reduced the physical burden placed on elders, enabled many women to leave their children in the safety of the village, and represented an important social adaptation to reduce vulnerability to HEI.

\section{Boga Khwe were more vulnerable than people of other ethnicities because of access}

Socio-political factors that influenced landscape use through settlement patterns and agricultural development meant that Boga Khwe were more vulnerable to HEI, in particular during the dry winter months when elephants tended to cross the main road near the village to access water from the Delta floods. People who settled in the north and central sections of the village had greater access to open woodlands (Fig. 7). Specifically, North Mokgacha households were BaHambukushu-headed (84\%), with access to open canopy dry woodlands to the north and east of the village. Central Mokgacha households were Bayei-headed $(83 \%)$ with access to open canopy woodlands to the east of the village. In contrast, $57 \%$ of South Mokgacha households were Boga Khwe-headed. The southern section of the village had the highest concentration of nearby agricultural fields, all of which are fenced with poles cut from the surrounding woodlands. Not only did this mean that these areas were poor places for firewood resources, but they were difficult to circumvent because of the barricade of fencing. Instead, Boga Khwe residents often harvested to the west, in the closed canopy wetland forest that lined the Delta. There, they were more vulnerable to HEI because the forest was denser, visibility was low, and elephants were likely to move through to access water.

Fig. 7. Mokgacha village by residence section, with a 1kilometer buffer around the village edge to indicate where people often harvest firewood.

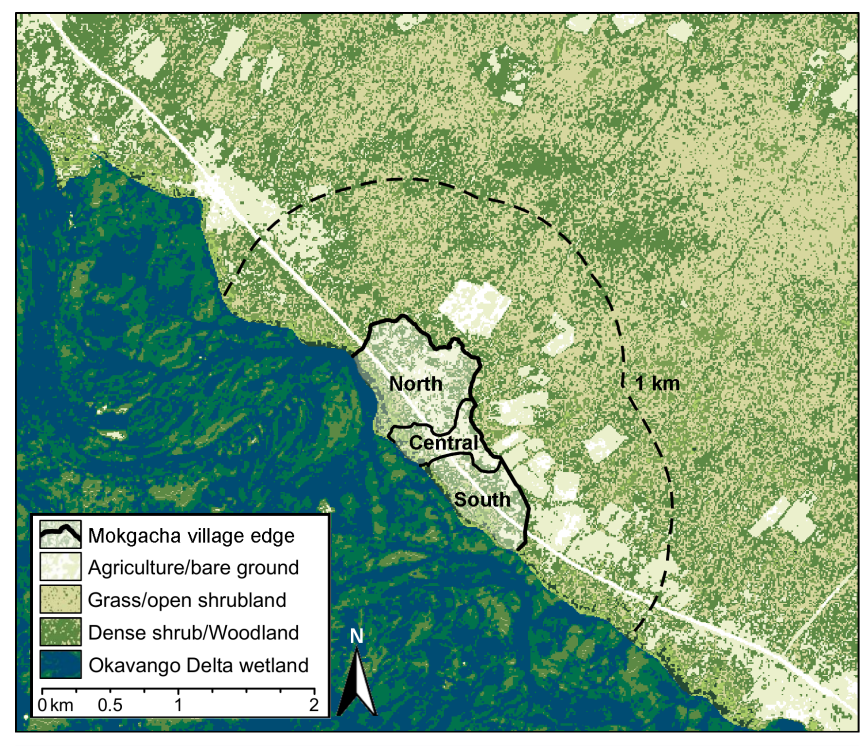

This is exemplified in two field notes, taken just one day apart in late May 2018 when elephants had begun to regularly frequent the village and its surroundings. During one harvest with a Boga Khwe woman living in South Mokgacha, we stopped briefly in our tracks once we saw how fresh the elephant signs of dung and urine were just on the outskirts of the village on our way to our regular harvest site. From our field notes, we wrote: "We saw a young boy walking our way from the Delta. She [our focal follow participant] asked the boy if he had seen elephants out where he came from, and he responded "no." We took the boy's path towards the Delta to be sure." There, the vegetation always remains green and leafy even in the driest of times, and contrasts to our experience harvesting the following day in North Mokgacha with a BaHambukushu woman. We wrote:

Although it was close to 9 AM when we left, we could
still hear the elephants calling each other in the bush, not
far from the village. We took the main path... I counted
the number of times elephants took the perpendicular
paths early in the morning. After I surpassed 20
perpendicular paths, I stopped counting... I was amazed
at how quickly the vibrantly green vegetation - trees and
shrubs - have desiccated, leaving only brown seed pods
hanging from branches of thirsty trees... and visibility is
much higher than it has been for a while in this short shrub
woodland thicket.

Ethnicity influenced vulnerability to HEI through both time and space, furthering our findings that culture is an overlooked but central component of HEI.

\section{CONCLUSION}

Our research showed that risk perception, vulnerability, and adaptation are useful theoretical lenses to understand how people share space and reduce unwanted interactions with elephants. We used an intersectional lens to show that perceived risk, adaptation, and vulnerability are influenced by abilities of the individual, broader institutions, including culture and land use, and livelihood demands. Because we examined HEI through the lens of an understudied resource, firewood, we showed that conflict is not the only outcome of HEI. People perceived risk to elephants and actively adapted to changing environmental and social conditions to reduce their vulnerability. Given the increased availability of firewood as a direct result of elephant movement, we have shown that people adapted to reduce the costs of sharing the landscape with elephants.

Like previous studies (Rust and Taylor 2016, Homewood et al. 2020), a focus on the intersectionality of both fixed and mutable identities, including gender, age, ability, and ethnicity, allowed us to show that not all people had a singular, shared experienced with HEI. Of particular interest is the blanket assumption that women are most vulnerable to HEI, and previous studies reveal incalculable costs borne by women during livelihood activities in an elephant landscape (Ogra 2008, DeMotts and Hoon 2012). However, we showed that some women are less vulnerable to HEI during firewood harvest because they have adapted in gendernormative ways, because of group-oriented livelihood strategies and general flexibility of their natural resource-based livelihoods. In contrast, men, by and large, have been overlooked in the literature on vulnerability to $\mathrm{HEI}$, and we demonstrated that more attention is needed to understand how gender dynamics play out in wildlife-rich and hazardous social-ecological landscapes. This may be due to the focus of many HEI studies on conflict over crops (e.g., Hoare 1999, Sitati and Walpole 2006), and future research should use an integrative perspective to incorporate diverse livelihoods within the cultural landscape. 
For the elderly, issues of vision loss from cataracts and general hearing loss were common health problems with big consequences where people live with elephants. Medical interventions, such as cataracts surgery or the provision of hearing aids, may not only help the elderly age better, but can potentially help people feel empowered with greater freedom despite other challenges associated with rural life in Botswana. Our study also showed that ethnicity mattered because of settlement patterns that have consequence beyond development. These findings are similar to Shinn and others (2014) and highlight the need for more research that examines the relationships between ethnicity, livelihood and settlement decisions, and vulnerability. More research should explore the role of class in HEI, in particular given the ability for people with vehicles to harvest copious amounts of firewood in elephant corridors where trees have been denuded, visibility is high, and perceived risk may be low.

Conservation interests should focus their efforts on developing a better understanding of the often-hidden dimensions of vulnerability and build solutions that reinforce culturally relevant adaptations. These may focus on resource sharing and collective resource harvest groups given the importance of collective efforts at reducing HEI. Where it is not possible for people to move in groups, in particular around cattle-based livelihoods, more research is needed to identify alternative strategies to reduce vulnerability of ranchers. Like recent initiatives in the area that build from local knowledge for agricultural development and conservation (e.g., Ecoexist Project's elephant corridors, http:// www.ecoexistproject.org/reporting-back/blog/protecting-elephantcorridors/), integrative approaches to village planning and livelihood development should incorporate a holistic examination of resource needs for shared land and resource use with elephants.

Responses to this article can be read online at: http://www.ecologyandsociety.org/issues/responses. $\mathrm{php} / 12001$

\section{Acknowledgments:}

The authors would like to sincerely thank the people of Mokgacha village and neighboring cattleposts for their participation in this research and for kindly opening their homes and hearts to LR. The authors would also like to graciously acknowledge Ipolokeng Katholo, who helped with linguistic and cultural translation, and without whom this work would not have been possible. The authors also acknowledge the support from the Government of Botswana and the Ministry of Environment, Wildlife, and Tourism (permit \# EWT 8/36/4 XXXVII (15)). This research would not have been possible without funding from the U.S. Fulbright Student Research Award, Texas A\&M's Applied Biodiversity Sciences Program (National Science Foundation-NSF-DGE-0654377), and the Howard G. Buffet Foundation. Additionally, we thank Dr. Erin Buchholtz for providing all study site maps, Dr. Jennifer ZavelataCheek for her helpful feedback on early drafts of paper, and the two anonymous reviewers who provided helpful feedback.

\section{Data Availability:}

The data that support the findings of this study are openly available in Open Science Framework at https:/losf.iolajdtel. Ethical approval for this research study was granted by Texas A\&M's Institutional Review Board, study \#IRB2016-0255D.

\section{LITERATURE CITED}

Agarwal, B. 1986. Cold hearths and barren slopes: The woodfuel crisis in the third world. Vol. 40. Zed Books, London, UK.

Alvard, M. S. 1993. Testing the "ecologically noble savage" hypothesis: interspecific prey choice by Piro hunters of Amazonian Peru. Human Ecology 21(4):355-387. https://doi. org/10.1007/BF00891140

Arntzen, J. W., and D. L. Kgathi. 1984. Some of the determinants of the consumption of firewood energy in developing countries: the case of rural Botswana. Pula: Botswana Journal of African Studies 4(1):24-34.

Bernard, H. R. 2006. Research methods in anthropology: qualitative and quantitative approaches. Fourth edition. AltaMira Press, Lanham, Maryland, USA.

Boholm, A. 2003. The cultural nature of risk: can there be an anthropology of uncertainty? Ethnos 68(2):159-178. https://doi. org/10.1080/0014184032000097722

Buchholtz, E. K., L. E. Redmore, L. A. Fitzgerald, A. Stronza, A. C. Songhurst, and G. McCulloch. 2019. Temporal partitioning and overlapping use of a shared natural resource by people and elephants. Frontiers in Ecology and Evolution 7:117. https://doi. org/10.3389/fevo.2019.00117

Cannon, T. 2008. Reducing people's vulnerability to natural hazards: communities and resilience. WIDER Research Paper 2008/34. United Nations University, World Institute for Development Economics Research, Helsinki, Finland. [online] URL: https://www.econstor.eu/bitstream/10419/45089/1/571444865. pdf

Carr, E. R., and M. C. Thompson. 2014. Gender and climate change adaptation in agrarian settings: current thinking, new directions, and research frontiers. Geography Compass 8 (3):182-197. https://doi.org/10.1111/gec3.12121

Carter, N. H., and J. D. Linnell. 2016. Co-adaptation is key to coexisting with large carnivores. Trends in Ecology and Evolution 31(8):575-578. https://doi.org/10.1016/j.tree.2016.05.006

Carter, N. H., B. K. Shrestha, J. B. Karki, N. M. B. Pradhan, and J. Liu. 2012. Coexistence between wildlife and humans at fine spatial scales. Proceedings of the National Academy of Sciences 109(38):15360-15365. https://doi.org/10.1073/pnas.1210490109

Central Statistics Office(CSO). 2001.2001 Population and housing census: enumerator's manual. Government Printer, Gaborone, Botswana.

Central Statistics Office(CSO). 2011.2011 Population and housing census. Government Printer, Gaborone, Botswana.

Charles, T. 2018. Elephant kills another man in Seronga. Mmegi online, 10 September. [online] URL: https://www.mmegi.bw/ index.php?aid $=77484 \&$ dir $=2018 /$ september $/ 10$ 
Chase, M. J., S. Schlossberg, C. R. Griffin, P. J. C. Bouché, S. W. Djene, P. W. Elkan, S. Ferreira, F. Grossman, E. M. Kohi, K. Landen, P. Omondi, A. Peltier, S. A. J. Selier, and R. Sutcliffe. 2016. Continent-wide survey reveals massive decline in African savannah elephants. PeerJ 4:e2354. https://doi.org/10.7717/ peerj. 2354

Chaukura, I., G. Satau, R. Lubilo, and H. Nathinge. 2020. RE: Communities response to Nowak, K., Lee, P., Marino, J., Mkono, M., Mumby, H., Dobson, A., Harvey, R., Lindsay, K., Luseeau, D., Sillero-Zubiri, C., and 71 signatories (2019). Trophy hunting: Bans create opening for change. Science 366(6464):434-435. https://science.sciencemag.org/content/366/6464/434/tab-e-letters

Crenshaw, K. 1991. Mapping the margins: intersectionality, identity politics, and violence against women of color. Stanford Law Review 43:1241-1299. https://doi.org/10.2307/1229039

Demetriades, J., and E. Esplen. 2008. The gender dimensions of poverty and climate change adaptation. IDS Bulletin 39(4):24-31. https://doi.org/10.1111/j.1759-5436.2008.tb00473.x

DeMotts, R., and P. Hoon. 2012. Whose elephants? conserving, compensating, and competing in Northern Botswana. Society and Natural Resources 25(9):837-851. https://doi.org/10.1080/08941920.2011 .638362

Dickman, A. J. 2010. Complexities of conflict: the importance of considering social factors for effectively resolving human-wildlife conflict: social factors affecting human-wildlife conflict resolution. Animal Conservation 13(5):458-466. https://doi. org/10.1111/j.1469-1795.2010.00368.X

Djoudi, H., B. Locatelli, C. Vaast, K. Asher, M. Brockhaus, and B. Basnett Sijapati. 2016. Beyond dichotomies: gender and intersecting inequalities in climate change studies. Ambio 45 (3):248-262. https://doi.org/10.1007/s13280-016-0825-2

Doubleday, K. F. 2020. Tigers and "good Indian wives": feminist political ecology exposing the gender-based violence of humanwildlife conflict in Rajasthan, India. Annals of the American Association of Geographers 110(5):1521-1539. https://doi. org/10.1080/24694452.2020.1723396

Emerson, R. M. 2001. Producing ethnographies. Theory, evidences and representation. Pages 239-259 in R. M. Emerson, editor. Contemporary field research: perspectives and formulations. Waveland, Long Grove, Illinois, USA.

Government of Botswana. 1968. The Forest Act. Government Printing, Gaborone, Botswana.

Guest, G., A. Bunce, and L. Johnson. 2006. How many interviews are enough? An experiment with data saturation and variability. Field Methods 18(1):59-82. https://doi.org/10.1177/1525822x05279903

Hill, C. M. 2004. Farmers' perspectives of conflict at the wildlifeagriculture boundary: some lessons learned from African subsistence farmers. Human Dimensions of Wildlife 9(4):279-286. https://doi.org/10.1080/10871200490505710

Hoare, R. E. 1999. Determinants of human-elephant conflict in a land-use mosaic. Journal of Applied Ecology 36(5):689-700. https://doi.org/10.1046/j.1365-2664.1999.00437.x
Homewood, K., M. R. Nielsen, and A. Keane. 2020. Women, wellbeing and wildlife management areas in Tanzania. Journal of Peasant Studies. https://doi.org/10.1080/03066150.2020.1726323

Kasperson, R. E., O. Renn, P. Slovic, H. S. Brown, J. Emel, R. Goble, J. X. Kasperson, and S. Ratick. 1988. The social amplification of risk: a conceptual framework. Risk Analysis 8 (2):177-187. https://doi.org/10.1111/j.1539-6924.1988.tb01168.x

Kgathi, D., and C. Mlotshwa. 1997. Fuelwood procurement, consumption and substitution in selected areas of Botswana. Pages 10-63 in D. L. Kgathi, H. O. Hall, A. Hategeka, and M. B. M. Sekhwela, editors. Biomass energy policy in Africa: selected case studies. Zed Books, London, UK.

Lee, P. C., and M. D. Graham. 2006. African elephants Loxodonta africana and human-elephant interactions: implications for conservation. International Zoo Yearbook 40(1):9-19. https://doi. org/10.1111/j.1748-1090.2006.00009.x

Lute, M. L., and M. L. Gore. 2019. Broadening the aperture on coexistence with wildlife through the lenses of identity, risk and morals. Pages 45-64 in B. Frank, J. A. Glikman, and S. Marchini, editors. Human-wildlife interactions: turning conflict into coexistence. Cambridge University Press, Cambridge, UK. https://doi.org/10.1017/9781108235730.006

MacGregor, S. 2009. A stranger silence still: the need for feminist social research on climate change. Sociological Review 57 (2_suppl):124-140. https://doi.org/10.1111/j.1467-954X.2010.01889. $\underline{\mathrm{X}}$

Mariki, S. B., H. Svarstad, and T. A. Benjaminsen. 2015. Elephants over the cliff: explaining wildlife killings in Tanzania. Land Use Policy 44:19-30. https://doi.org/10.1016/j.

landusepol.2014.10.018

Maru, Y. T., M. S. Smith, A. Sparrow, P. F. Pinho, and O. P. Dube. 2014. A linked vulnerability and resilience framework for adaptation pathways in remote disadvantaged communities. Global Environmental Change 28:337-350. https://doi.org/10.1016/ j.gloenvcha.2013.12.007

Mayberry, A. L., A. J. Hovorka, and K. E. Evans. 2017. Wellbeing impacts of human-elephant conflict in Khumaga, Botswana: exploring visible and hidden dimensions. Conservation and Society 15(3):280-291.

Mbaiwa, J. E. 2003. The socio-economic and environmental impacts of tourism development on the Okavango Delta, northwestern Botswana. Journal of Arid Environments 54(2):447-467. https://doi.org/10.1006/jare.2002.1101

McCarthy, J. M., T. Gumbricht, T. McCarthy, P. Frost, K. Wessels, and F. Seidel. 2003. Flooding patterns of the Okavango wetland in Botswana between 1972 and 2000. Ambio 32(7):453-457. https://doi.org/10.1579/0044-7447-32.7.453

McCarthy, T. S., G. R. Cooper, P. Tyson, and W. N. Ellery. 2000. Seasonal flooding in the Okavango Delta, Botswana-recent history and future prospects. South African Journal of Science 96 (1):25-33.

Miller, F., H. Osbahr, E. Boyd, F. Thomalla, S. Bharawani, G. Ziervogel, B. Walker, J. Birkmann, S. van der Leeuw, J. Rockström, 
J. Hinkel, T. Downing, C. Folke, and D. Nelson. 2010. Resilience and vulnerability: complementary or conflicting concepts? Ecology and Society 15(3):11. https://doi.org/10.5751/es-03378-150311

Mmopelwa, G., J. N. Blignaut, and R. Hassan. 2009. Direct use values of selected vegetation resources in the Okavango Delta wetland. South African Journal of Economic and Management Sciences 12(2):242-255. https://doi.org/10.4102/sajems.v12i2.279

Mollett, S., and C. Faria. 2013. Messing with gender in feminist political ecology. Geoforum 45:116-125. https://doi.org/10.1016/j. geoforum.2012.10.009

Moon, K., T. Brewer, S. R. Januchowski-Hartley, V. M. Adams, and D. A. Blackman. 2016. A guideline to improve qualitative social science publishing in ecology and conservation journals. Ecology and Society 21(3):17. https://doi.org/10.5751/ES-08663-210317

Müller-Mahn, D. 2012. The spatial dimension of risk: how geography shapes the emergence of riskscapes. Routledge, London, UK. https://doi.org/10.4324/9780203109595

Naughton-Treves, L. 2001. Farmers, wildlife, and the forest fringe. Pages 369-384 in W. Weber, L. J. T. White, A. Vedder, and L. Naughton-Treves, editors. African rainforest ecology: an interdisciplinary perspective. Yale University Press, New Haven, Connecticut, USA.

Naughton, L., R. Rose, and A. Treves. 1999. The social dimensions of human-elephant conflict in Africa: a literature review and case studies from Uganda and Cameroon. A Report to the African Elephant Specialist Group, Human-Elephant Conflict Task Force, International Union for Conservation of Nature, Gland, Switzerland.

Naughton-Treves, L., and A. Treves. 2005. Socio-ecological factors shaping local support for wildlife: crop-raiding by elephants and other wildlife in Africa. Pages 252-277 in R. Woodroffe, S. Thirgood, and A. Rabinowitz, editors. People and wildlife: conflict or coexistence. Cambridge University Press, Cambridge, UK. https://doi.org/10.1017/CBO9780511614774.017

Nelson, A., P. Bidwell, and C. Sillero-Zubiri. 2003. A review of human-elephant conflict management strategies. People and Wildlife Initiative. Wildlife Conservation Research Unit, Oxford University, Oxford, UK.

Ogra, M. V. 2008. Human-wildlife conflict and gender in protected area borderlands: a case study of costs, perceptions, and vulnerabilities from Uttarakhand (Uttaranchal), India. Geoforum 39(3):1408-1422. https://doi.org/10.1016/j. geoforum.2007.12.004

O'Reilly, K. 2005. Ethnographic methods. Routledge, New York, New York, USA.

Oswin Perera, B. 2009. The human-elephant conflict: a review of current status and mitigation methods. Gajah 30:41-52.

Pelling, M. 2011. Adaptation to climate change: from resilience to transformation. Routledge, London, UK. https://doi. org/10.4324/9780203889046

Pozo, R. A., T. Coulson, G. McCulloch, A. L. Stronza, and A. C. Songhurst. 2017. Determining baselines for human-elephant conflict: a matter of time. PLOS ONE 12(6):e0178840. https://doi. org/10.1371/journal.pone. 0178840
Pozo, R. A., E. G. LeFlore, A. B. Duthie, N. Bunnefeld, I. L. Jones, J. Minderman, O. S. Rakotonarivo, and J. J. Cusack. 2020. A multispecies assessment of wildlife impacts on local community livelihoods. Conservation Biology. https://doi.org/10.1111/ cobi. 13565

Ravera, F., B. Martín-López, U. Pascual, and A. Drucker. 2016. The diversity of gendered adaptation strategies to climate change of Indian farmers: a feminist intersectional approach. Ambio 45 (3):335-351. https://doi.org/10.1007/s13280-016-0833-2

Redpath, S. M., J. D. Linnell, M. Festa-Bianchet, L. Boitani, N. Bunnefeld, A. Dickman, R. J. Gutiérrez, R. J. Irvine, M. Johansson, A. Majić, et al. 2017. Don't forget to look downcollaborative approaches to predator conservation. Biological Reviews 92(4):2157-2163. https://doi.org/10.1111/brv.12326

Rust, N. A., and N. Taylor. 2016. Carnivores, colonization, and conflict: a qualitative case study on the intersectional persecution of predators and people in Namibia. Anthrozoös 29(4):653-667. https://doi.org/10.1080/08927936.2016.1228758

Ryder, S. S. 2017. A bridge to challenging environmental inequality: intersectionality, environmental justice, and disaster vulnerability. Social Thought and Research 34:85-115. https://doi. org/10.17161/1808.25571

Sale, J. E., L. H. Lohfeld, and K. Brazil. 2002. Revisiting the quantitative-qualitative debate: implications for mixed-methods research. Quality and Quantity 36(1):43-53.

Shinn, J. E., B. King, K. R. Young, and K. A. Crews. 2014. Variable adaptations: micro-politics of environmental displacement in the Okavango Delta, Botswana. Geoforum 57:21-29. https:// doi.org/10.1016/j.geoforum.2014.08.006

Sitati, N. W., and M. J. Walpole. 2006. Assessing farm-based measures for mitigating human-elephant conflict in Transmara District, Kenya. Oryx 40(3):279-286. https://doi.org/10.1017/ $\underline{\mathrm{S} 0030605306000834}$

Slovic, P. 2000. Perception of risk. Pages 220-231 in P. Slovic, editor. The perception of risk. Routledge, London, UK.

Slovic, P., H. Kunreuther, and G. White. 2000. Decision processes, rationality and adjustment to natural hazards. Pages 1-31 in $\mathrm{P}$. Slovic, editor. The perception of risk. Routledge, London, UK.

Smit, B., and J. Wandel. 2006. Adaptation, adaptive capacity and vulnerability. Global Environmental Change 16(3):282-292. https://doi.org/10.1016/j.gloenvcha.2006.03.008

Starr, C. 1969. Social benefit versus technological risk. Science 165(3899):1232-1238. https://doi.org/10.1126/science.165.3899.1232

Sukumar, R. 2003. The living elephants: evolutionary ecology, behaviour, and conservation. Oxford University Press, Oxford, UK.

Tipping-Woods, D. 2018. Living with elephants in Botswana. World Wildlife Fund, Washington, D.C., USA. [online] URL: https://www.worldwildlife.org/magazine/issues/winter-2018/articles/ living-with-elephants-in-botswana--2

Turner II, B. L., P. A. Matson, J. J. McCarthy, R. W. Corell, L. Christensen, N. Eckley, G. K. Hovelsrud-Broda, J. X. Kasperson, R. E. Kasperson, A. Luers, M. L. Martello, S. Mathiesen, R. Naylor, C. Polsky, A. Pulsipher, A. Schiller, H. Selin, and N. Tyler. 
2003. Illustrating the coupled human-environment system for vulnerability analysis: three case studies. Proceedings of the National Academy of Sciences 100(14):8080-8085. https://doi. org/10.1073/pnas.1231334100

Vickery, J. 2018. Using an intersectional approach to advance understanding of homeless persons' vulnerability to disaster. Environmental Sociology 4(1):136-147. https://doi. org/10.1080/23251042.2017.1408549

Witter, R. 2013. Elephant-induced displacement and the power of choice: moral narratives about resettlement in Mozambique's Limpopo National Park. Conservation and Society 11(4):406-419. https://doi.org/10.4103/0972-4923.125756

Wojcik, D. J. 2011. Communication, social networks, and perceptions of water and wildlife in the Okavango Delta, Botswana. Dissertation. University of Florida, Gainesville, Florida, USA.

Wolcott, H. F. 2005. The art of fieldwork. Rowman Altamira, Walnut Creek, California, USA. 